\title{
Modelling extreme streamflows under non-stationary conditions in the Ouémé River basin, Benin, West Africa
}

\author{
JEAN HOUNKPE ${ }^{1,2}$, ABEL A. AFOUDA ${ }^{2}$, BERND DIEKKRÜGER $^{3} \&$ \\ FABIEN HOUNTONDJI ${ }^{4}$ \\ 1 West Africa Science Service Centre on Climate change and Adapted Land Use/ University of Abomey-Calavi, PO Box \\ 2008 Abomey-Calavi, Benin Republic \\ jeanhounkpe@gmail.com \\ 2 Laboratory of Applied Hydrology, University of Abomey-Calavi, Benin \\ 3 Department of Geography, University of Bonn, Germany \\ 4 University of Parakou, Benin
}

\section{INTRODUCTION}

Recently, many countries across West Africa have suffered from catastrophic floods that affected thousands of people with loss of lives, and damage to properties. Floods have become increasingly frequent. Within the context of global warming, the hypothesis of stationarity of observed data required to perform classical flood frequency analysis is no longer valid. Assuming stationarity may results in an underestimation of the flood risk or over-sizing of flood protection measures. The aim of this study was to improve flood frequency analysis by introducing a non-stationary probabilistic model to estimate recurrence of extreme flood events.

\section{MATERIAL AND METHODS}

The river discharge data used are from the National Water Directorate (Direction Générale de l'Eau, DGEau), which were analysed for annual maximal discharge. A statistical model to predict the probability and magnitude of floods in non-stationary conditions was developed. The model uses a time-dependent and/or covariates dependent Generalized Extreme Value (GEV) distribution to fit the Annual Maximal (AM) discharge, and was applied to five gauging stations of the Ouémé River basin in Benin Republic, West Africa. Different combinations of the model parameters which vary with respect to time and/or covariates (sea level pressure and sea surface temperature) (Table 1) were explored against a stationary model based on three criteria of goodness of fit: the Likelihood-Ratio test, the Akaike Information Criterion (AIC) and the Bayesian Information Criteria (BIC). The non-stationarity in the location parameter as well as the design value for the 25 and 50 year recurrence intervals were studied.

Table 1 Different GEV models parameter. Cov is used for the covariate which may be sea surface temperature (SST) or sea level pressure (SLP) of the Gulf of Guinea.

\begin{tabular}{llll}
\hline Model & Location parameter $\mu$ & Scale parameter $\sigma$ & Shape parameter $\kappa$ \\
\hline GEV-1 & $\mu(\mathrm{t})=$ constant & $\sigma=$ constant & $\kappa=$ constant \\
GEV-2 & $\mu(t)=\mu_{0}+\mu_{1} \times \operatorname{Cov}(t)$ & $\sigma=$ constant & $\kappa=$ constant \\
GEV-3 & $\mu(t)=\mu_{0}+\mu_{1} \times \operatorname{Cov}(t)$ & $\log (\sigma)=\sigma_{0}+\sigma_{1} \times \operatorname{Cov}(t)$ & $\kappa=$ constant \\
GEV-4 & $\mu(t)=\mu_{0}+\mu_{1} \times t$ & $\sigma=$ constant & $\kappa=$ constant \\
GEV-5 & $\mu(t)=\mu_{0}+\mu_{1} \times t$ & $\log (\sigma)=\sigma_{0}+\sigma_{1} \times t$ & $\kappa=$ constant \\
GEV-6 & $\mu(t)=\mu_{0}+\mu_{1} \times t+\mu_{2} \times \operatorname{Cov}(t)$ & $\sigma=$ constant & $\kappa=$ constant \\
GEV-7 & $\mu(t)=\mu_{0}+\mu_{1} \times \operatorname{Cov}(t)$ & $\log (\sigma)=\sigma_{0}+\sigma_{1} \times t$ & $\kappa=$ constant \\
\hline
\end{tabular}

\section{RESULTS AND DISCUSSION}

The Mann-Kendall and Spearman's rho trend tests show that, at the 5\% significance level, there is no significant trend in the observed annual maximum discharge over the observation period 1952 to 2009. Nevertheless, the Hubert segmentation test combined with the non-parametric Pettitt test 
shows that there are break points in data for some discharge stations. The existence of abrupt changes is a valid hypothesis for introducing non-stationarity in the estimation (López and Francés 2013).

A flood frequency analysis (FFA) of these data reveals that the non-stationary model is more adequate to explain a substantial amount of variation in the data. All the used criteria of goodness of fit converge and show that the GEV-2 model is the most appropriate to analyse the flood data for the study area. This model considers a linear trend in the covariates in the location parameter while the others parameters remained constant (Fig. 1). These results are consistent with the finding of Aissaoui-Fqayeh et al. (2009).

The analysis of the 25-year and 50-year design flood shows that assuming return periods to be stationary leads to high uncertainties in the estimation. This case study scrutinizes the hypothesis of stationarity in estimating flood events and shows the strong need to account for the change over time in the FFA. In this context, the planning of water-related infrastructures needs to be updated considering non-stationarity in order to reduce the vulnerability of human beings and goods exposed to flood risk.
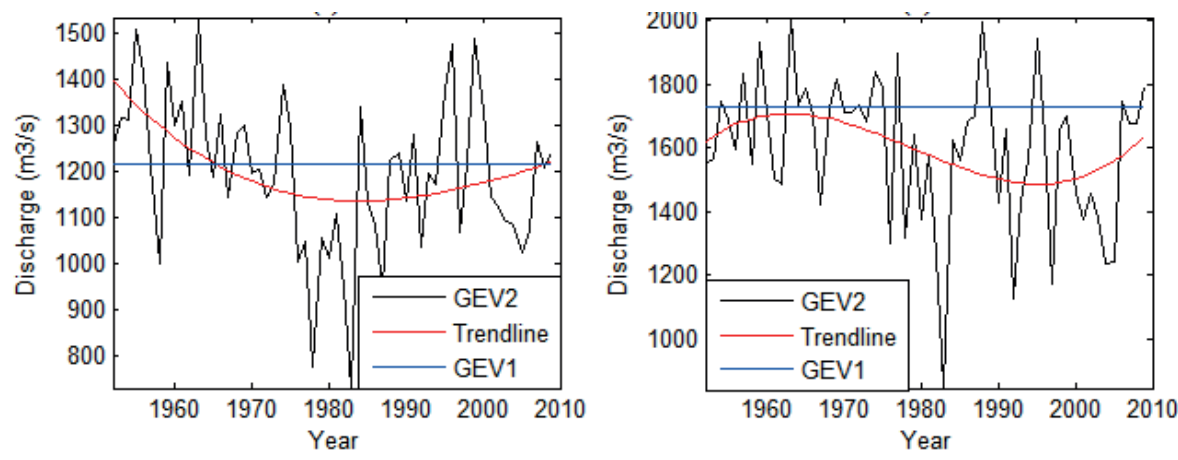

Fig. 125 -year design flood values of the annual maximal discharge for the study period (1952-2009) at Bonou (left) and Savè (right) based on the GEV2 model (non-stationary) and GEV1 (stationary).

\section{CONCLUSION}

An extreme-value non-stationary model was developed in this study to analyse the frequency and magnitude of flood in the main sub-basins of Ouémé River. Results show that it is necessary to incorporate non-stationarity to extreme FFA through a linkage between climate variables or time and the distribution parameters in order to improve the estimation and to ensure efficient protection of life and property against water related hazards such floods.

Acknowledgements This work was funded by the German Federal Ministry of Education and Research (BMBF) through the West African Science Service Centre on Climate Change and Adapted Land Use (WASCAL).

\section{REFERENCES}

Aissaoui-Fqayeh, I. et al. (2009) Développement du modèle log-normal non-stationnaire et comparaison avec le modèle GEV non-stationnaire. Hydrological Sciences Journal, 54(6), 1141-1156.

López, J. and Francés, F. (2013) Non-stationary flood frequency analysis in continental Spanish rivers, using climate and reservoir indices as external covariates. Hydrology and Earth System Sciences, 17(8), 3189-3203. 